\title{
A Comparison of the Logical Structure of Marx and Marcuse's Alienation Theory
}

\author{
Yu Feng ${ }^{1}$ \\ ${ }^{1}$ School of Philosophy, Beijing Normal University, Beijing, China \\ Correspondence: Yu Feng, School of Philosophy, Beijing Normal University, No. 19, XinJieKouWai St. HaiDian \\ District, Beijing 100875, P. R. China. Tel: 135-2186-7715. E-mail: $201521020001 @$ mail.bnu.edu.cn
}

Received: July 2, 2020

doi:10.5539/ass.v16n8p96
Accepted: July 20, $2020 \quad$ Online Published: July 31, 2020

URL: https://doi.org/10.5539/ass.v16n8p96

\begin{abstract}
"Economic \& Philosophic Manuscripts of 1844" is one of Marx's early important works. In the manuscript, Marx, based on his criticism of "alienated labor", provided a new method or a new perspective for people to analyze practical problems. Marcuse inherited Marx's theory of "alienation" and depicted the historical prospect of "comprehensive alienation" in developed industrial society. Starting from Hegel, this paper analyzes and reveals the basic structure of alienation logic. Based on this, a systematic and comprehensive comparison is made between Marx's theory of alienation and Marcuse's theory of alienation from two aspects: the internal logic of alienation and the external logic of alienation. The final aim is to show Marcuse's inheritance and transcendence of Marx's theory of alienation. Marcuse basically followed the logical structure of Marx's alienation theory and abandoned the application of this concept in speculative sense. Marcuse based on the reality of the development of capitalism in new era, developed it into a theory of social criticism, and even regarded it as the inner motive force of the real political revolution.
\end{abstract}

Keywords: alienation, alienated labor, comprehensive alienation, logical structure

\section{Introduction}

The Manuscripts was written from the end of May or early June to August 1844 and was not published during Marx's lifetime. The "Complete Works of Marx and Engels", part 1, Volume 3, MEGA, published in the Soviet Union in 1932, published all the manuscripts in original German and were entitled "Economic \& Philosophic Manuscripts of 1844". In Marx's Manuscripts, the theory of "alienated labor" is at the core. The important significance of this theory lies not only in Marx's disclosure of the working conditions and tragic fate of the working class under capitalist conditions, but more importantly, he provides a new method or a new perspective for people to analyze practical problems. In order to make better use of this method and exert its social critical function, a deep understanding of the logical structure of alienated labor is not only of theoretical significance but also of practical significance.

However, the writing of the Manuscript was nearly a century away from publication. Capitalism, after this period of development, did not decline, but prospered, showing an unprecedented trend of development. Based on the analysis of the development form of capitalism in the new era, Marcuse inherited and criticized Marx's "alienated labor" and painted a picture of "comprehensive alienation" in the developed industrial society. This idea was embodied in the book "One Dimensional Man: Studies in the Ideology of Advanced Industrial Society", published in 1964. Marcuse's criticism of the developed industrial society was not limited to wage labor, but made a systematic and comprehensive analysis and criticism from different aspects such as politics, life, thought, culture and language, etc. He pointed out a new path for people to "sublate" alienation and realize the free and all-round development of people- "art alienation". By comparing Marx's "alienated labor" with Marcuse's "comprehensive alienation", this article attempts to clarify the difference in logic structure between the two, and expounds several relevant thoughts.

The question that this paper will answer is what is the logical structure of alienation? What are the differences between Marx and Marcuse's alienation theory? And do these differences mean a kind of progress? In response to the above questions, this article mainly adopts the following research methods: First, the literature method. This paper mainly focuses on the alienation theory of Marx and Marcuse, from which the internal logic of the two is excavated and compared. In order to accomplish this task well, we should first return to the text. Through 
a comprehensive and thorough analysis of the text, we can support our viewpoints and conclusions with the classic writers' own statements, and make the article more reasonable and convincing. Therefore, the literature method is the most basic research method to be adopted in this paper. Second, in order to clearly show the evolution of the theory of alienation from Hegel to Marx and then to Marcuse, and to answer the question whether Marcuse has further developed and improved the theory of alienation on the basis of inheriting Marx's concept of alienation, we need to use the comparative research method to compare the similarities and differences of the concept of alienation between the two classic writers. Third, the combination of theory and fact. This article contains both abstract theories and objective facts. Facts are the only criterion for testing truth. The conclusions we draw should be consistent with the facts. Views that cannot be tested by facts are unconvincing.

\section{The Logical Structure of "Alienation"}

The German "Entfremgung" comes from the Latin "Alienatio", meaning "to be the other" or "become the other", which is translated into "alienation" in English. "Alienation" has two main meanings: one refers to "keep at a distance" or "become estranged" and the other refers to "transfer". Later it came to be used in philosophy, and as a philosophical term it had slightly different meanings, such as "self-denial", "counteraction" and "dissimilation". (Sun, 2002, pp. 409-410) Generally speaking, the subject becomes an object that is different from itself, the object in turn is opposite to the subject, and finally the subject makes the object return to itself by sublating the object. (Han, 2014, p. 330) Our research on "alienation" will be traced back to Hegel, because "alienation" was first used as the main philosophical concept from Hegel. Secondly, Marx did not form a unified logical structure of "alienated labor" in his "Manuscript". Finally, Marx's early thoughts were deeply influenced by Hegel, so we cannot talk about Marx's "alienated labor" without Hegel's theoretical background.

\subsection{The Internal Logic of "Alienation"}

Hegel starts from alienation (logically from infinite things, abstract and universal things), from entities, from absolute and immutable abstractions, that is to say, more general, he starts from religion and theology. In order to sublate infinite things, he sets realistic, sensual, real, finite and special things. (Marx \& Engels, 2002, p. 315) In other words, in order to go beyond the "absolute spirit" and create nature and human society, Hegel introduced the concept of "alienation". Nature and human society are alienated by absolute spirit and they are not only objectified things but also alienated things for the absolute spirit. "Alienation" is the key link for "absolute spirit" to construct nature and human society. As the subject, "absolute spirit" forms objects different from itself through "alienation" or "externalization". It is through this self-denial that the essential power of the subject itself is confirmed. The more powerful the object is against the subject, the more it can confirm the subject's own strength. The relationship between "absolute spirit" and its alienated objects can be regarded as the opposite relationship between subject and object. Since Hegel regards spirit as an absolute thing, the development of the spirit is self-development caused by its own reasons.

To sum up, the concept of alienation first presupposes a subject, which in Hegel's sense refers to "absolute spirit". The essence of the subject is not rigid and immutable, but realistic and alive. It can alienate or externalize an object which is alienated and opposite to itself, and this process is the result of the subject's self-movement. Therefore, "subject-object opposition" and "self-alienation" are the fundamental characteristics of the logical structure of alienation. (Han, 2014, p. 331) We call it "the internal logic of alienation". It should be noted that the opposition between the subject and the object is not absolute, and the object is not something completely different from the subject. In fact, the object is a subject in another form established by the subject through self-denial.

After Hegel, Feuerbach continued to use the concept of alienation in the sense of philosophical humanism. "Feuerbach believes that to understand history, we should not start from self-consciousness, but from people themselves. We must regard people and the essence of people based on nature as the supreme principle of philosophy. So instead of talking about the alienation of abstract self-consciousness, he talks about the alienation of human nature". (Sun, 2002, pp. 412-413) When Feuerbach criticized religion he pointed out that god is the other created by man who is alienated from man. All the powers and virtues possessed by god are created by human beings, which are the alienation of human nature. However, when Feuerbach used the concept of "alienation", he did not go beyond Hegel's logical framework. He just replaced Hegel's "absolute spirit" and the externalization of absolute spirit with "human essence" and "god". To the young Hegelians, the subject was replaced by "human", "self-consciousness" and "species-essence", while the object was replaced by god, state, politics, law, currency, etc. Although Hegel and the young Hegelians are opposite in theoretical inclination, they are completely consistent in the logical structure of the concept of alienation. (Han, 2014, p. 331) 


\subsection{The External Logic of "Alienation"}

In Hegel, the reason why absolute spirit becomes the object is that the spirit is the movement of becoming the other or the object of its own and sublating this other. In this movement, the direct things, the inexperienced things, that is, the abstract things, whether they belong to perceptual or purely ideological things, first alienate themselves, and then return to themselves from this alienation, in this way, things that have not been experienced before show their authenticity and become the property of consciousness. (Han, 2014, p. 458) Therefore, when "absolute spirit" has developed to a certain extent, it will realize that the object is only its own externalization, so the subject will sublate the alienated form of the object through another negation, overcome its objectivity and make it return to itself.

Professor Han Lixin refers to the process of "subject $\rightarrow$ alienation, externalization $\rightarrow$ object $\rightarrow$ sublation $\rightarrow$ subject" as "generalized alienation" or "good alienation". In this process, alienation acts as a positive force to make the subject realize itself in the process of self-movement. And "subject $\rightarrow$ alienation, externalization $\rightarrow$ object" is called "alienation in a narrow sense" or "evil alienation". This process highlights the negation of subject to object and the antagonistic nature between them. (Han, 2014, pp. 460-461) This paper refers to both as "external logic of alienation ". Does Marx's theory of "alienated labor" in the "Manuscript" continue to use the logical structure of "alienation" since Hegel?

\section{The Logical Structure of Marx's "Alienated Labor"}

\subsection{The Internal Logic of Marx's "Alienated Labor"}

Now we will re-examine the four aspects of "alienated labor" from the "internal logic of alienation". First of all, Marx points out that the externalization of the worker in his product not only means that his labor becomes an object, an external being, but also means that his labor as something different from him does not depend on him and exists outside him, and becomes an independent force in opposition to him; It means that the life he gives to the object is opposed to him as something hostile and different. (Marx \& Engels, 2002, p. 268) Second, labor is something external to the worker, that is, it does not belong to his essence; therefore, he is not affirming himself in his labor, but denying himself, not feeling happy, but feeling miserable, not freely exerting his physical strength and intelligence, but torturing his body and destroying his spirit. (Marx \& Engels, 2002, p. 270) Thirdly, "the whole character of a species, its species-character, is contained in the character of its life activity; and free, conscious activity is man's species-character". (Marx \& Engels, 2002, p. 273) But in estranged labor, "man's species-being, both nature and his spiritual species-property, into a being alien to him, into a means of his individual existence. It estranged from man his own body, as well as external nature and his spiritual aspect, his human aspect". (Marx \& Engels, 2002, p. 274) Finally, Marx pointed out that "an immediate consequence of the fact that man is estranged from the product of his labor, from his life activity, from his species-being, is the estrangement of man from man. When man confronts himself, he confronts the other man. What applies to a man's relation to his work, to the product of his labor and to himself, also holds of a man's relation to the other man, and to the other man's labor and object of labor". (Marx \& Engels, 2002, pp. 274-275)

In the first three aspects of alienated labor, Marx inherited the logical structure of "subject-object dichotomy" since Hegel. The subject is set in turn as "human labor", "laborer" and "man's species-being" and the corresponding alienated objects are "labor product", "labor activity" and "alien essence". The difference is that Hegel's alienation is a pure speculation, but Marx tries to use the ideological weapon of alienation to criticize social reality from the current economic facts. Before he criticized the estranged labor of the workers, he presupposed a primitive state or an "Ought to Be" state of the subject that was not alienated. It can be seen that Marx did not completely get rid of speculative features at that time. As for "self-alienation" in the internal logic, Marx clearly points out that "we have considered the act of estranging practical human activity, labor, in two of its aspects. (1) The relation of the worker to the product of labor as an alien object exercising power over him...... (2) The relation of labor to the act of production within the labor process....... Here we have self-estrangement". (Marx \& Engels, 2002, p. 271) There are also references to "self-estrangement" in the later sections of "Private Property and Communism". For example, "the transcendence of self-estrangement follows the same course as self-estrangement" (Marx \& Engels, 2002, p. 294) and "communism as the positive transcendence of private property as human self-estrangement" (Marx \& Engels, 2002, p. 297). However, Hegel and Marx's "self-estrangement" is not exactly the same. In Hegel's view, "alienation" is the product of the development of "absolute spirit" to a certain stage. This process is inevitable, unconditional, and separate from social history. However, in Marx's view, the "alienation" needs not only the intrinsic motivation of "labor", but also the external objective conditions of capitalist private ownership. Marx was still hovering between speculation and reality. The fourth aspect of alienated labor obviously does not conform to the above logic. In the 
first three aspects, the relationship between subject and object is "produce" and "be produced", "initiative" and" passivity", and they are not equal. But in the fourth aspect, alienation is used as an adjective, it is a description of the relationship between subject and "object". Although Marx did not clearly point out the specific meaning of "man" in the "the estrangement of man from man", but through the analysis of language and words, we can see that he is depicting a state of opposition between peer subjects. Therefore, the fourth aspect is obviously different from the previous three aspects in the logical structure.

\subsection{The External Logic of Marx's "Alienated Labor"}

Next, we will further examine the external logical structure of "alienated labor ". It can be seen in the "Estranged Labor and Private Property" that what is depicted here is an "alienation in a narrow sense" or "evil alienation", which aims to emphasize the confrontation between subject and object, and then criticize capitalism. Therefore, some scholars believe that Marx's criticism of alienated labor at that time takes moral evaluation as the priority. But then Marx turns to a "generalized alienation" in the section on "Private Property and Communism." "Communism as the positive transcendence of private property as human self-estrangement, and therefore as the real appropriation of the human essence by and for man; communism therefore as the complete return of man to himself as a social (i.e., human) being - a return accomplished consciously and embracing the entire wealth of previous development. This communism, as fully developed naturalism, equals humanism, and as fully developed humanism equals naturalism; it is the genuine resolution of the conflict between man and nature and between man and man - the true resolution of the strife between existence and essence, between objectification and self-confirmation, between freedom and necessity, between the individual and the species". (Marx \& Engels, 2002, p. 297) In summary, Marx's use of the concept of "alienation" during his writing of the "Manuscript" did not form a unified logical framework. Alienation is only a tool for Marx to criticize capitalism and demonstrate communism, which also exposes the immaturity of young Marx's thoughts to some extent.

\section{The Logical Structure of Marcuse's Theory of "Comprehensive Alienation"}

\subsection{The Internal Logic of "Comprehensive Alienation": Relationship between "Ought to Be" and "to Be"}

The publication of Marx's "Manuscript" and criticism of Hegel's philosophy further deepened Marcuse's thoughts and made him turn to Marx. Marx's exposition of human essence, especially labor in the philosophical sense, as well as his analysis and criticism of alienation had a great influence on Marcuse's later thoughts, especially on aesthetics. Unlike Marx's "alienated labor", Marcuse went beyond the economic sphere. By analyzing and criticizing the politics, life, thought, culture, language, and other fields in the developed industrial society, Marcuse pointed out how the developed industrial society successfully suppressed the negative, critical, and transcendental dimensions in people's hearts, and then make this society a one-dimensional society, and make people living in it a one-dimensional person. Marcuse uses the concept of alienation in a broader sense, so it is a "comprehensive alienation".

In political sphere, there is a marked convergence between the opposing factions. Bipartisan cooperation in foreign policy spans competing interest groups; the cooperation between the two parties also extends to domestic policies, and the political platforms of the major parties have become increasingly difficult to separate, even in terms of their hypocrisy and stale smell. (Marcuse, 2014, p. 18) In the field of life, the great abundance of material seems to be increasingly able to satisfy individual needs. But most of the current needs, such as rest and entertainment, life and consumption according to advertising are false needs. They are false because these needs are imposed on individuals from outside for specific social benefits and they are needs that perpetuate hardship, aggression, pain, and injustice. (Marcuse, 2014, p. 6) People are immersed in the pleasure brought by the satisfaction of needs, and lose the ability to think independently and to reflect and criticize the existing society. In the realm of thought, affirmative thinking has triumphed, and the inner dimension in which ideas against the status quo can be rooted has been weakened. This inner dimension is the power of negative thinking, that is, the home of rational critical forces, its loss is a reflection on the ideological consciousness of the material process of suppressing and reconciling the opposites in the developed industrial society. (Marcuse, 2014, pp. 10-11) Philosophy, with its positivist tendency in the dominant position, cannot provide critical negative power for getting rid of capitalist social alienation and various controls. In the field of culture, rational progress is eliminating the opposition between culture and social reality by eliminating opposing, alien and transcendental factors in high-level culture. (Marcuse, 2014, pp. 49-50) Literature and art are essentially alienation because it maintains and protects contradictions. (Marcuse, 2014, p. 53) However, the major rift between art and daily order, which is active in art alienation, has been gradually bridged by the developed technology society. (Marcuse, 2014, p. 55)

In Marcuse, the logical structure of the "subject-object dichotomy" since Hegel has gradually faded, replaced by 
a logical framework dominated by "Ought to Be"-"to Be". The logical structure of "Ought to Be-to Be" is the realization of the alienation logic of "subject-object dichotomy" and the inheritance and development of the latter "Inheritance" means that we just replaced the subject with the "Ought to Be" part and the object with the "to Be" part, and did not fundamentally dissolve the logical structure of "subject-object dichotomy". "Development" means that, if the "subject-object dichotomy" is a pure speculation or an abstract formula in Hegel's works, then in Marcuse this pure abstraction is realized, which is closely combined with social life and has the function of moral evaluation and value judgment. In short, "Ought to $\mathrm{Be}-$ to $\mathrm{Be}$ " is the realization of the "subject-object dichotomy". The difference between the two logical frameworks is not diametrically opposed, but two aspects of the same problem, that is, the relationship between the two can be understood as abstract and concrete, spiritual and material, theory and reality. Marx's "alienated labor" is the transition of this "realization" process. "Alienated labor" has not only traces of abstract speculation, but also a realistic theory based on "national economic facts". "Ought to Be" means that in developed industrial society, different subjects in the same field or system should maintain qualitative difference, but "reality" or "alienation" is the assimilation and convergence between different subjects. Obviously, there is alienation and opposition between "Ought to Be" and "to Be". Marcuse believes that the integration of capitalism is alienation. Where qualitative differences between conflicting interests manifest themselves as quantitative differences within established societies. (Marcuse, 2014, p. 19)

In Hegel or Marx, the object is the product of the subject's self-alienation, and the sublation of alienation is the return of the object to the subject. However, in Marcuse, alienation has lost the internal logical characteristic of "self-alienation", and replaced by the alienation and confrontation between the two equal subjects, that is, the opposition between "Ought to $\mathrm{Be}$ " and "to Be", ideal and reality. Since there is no self-movement between "Ought to Be" and "to Be", the return of "to Be" to "Ought to Be" can only be realized by "art alienation".

\subsection{The External Logic of "Comprehensive Alienation"}

In the context of "comprehensive alienation" in developed industrial society, Marcuse did not stop at criticizing social reality, but points out a new path - "art alienation" for people to sublate alienation and realize the free and all-round development of human beings. The reason why Marcuse turned from practical revolution to aesthetic revolution in the later period was that, first of all, from the perspective of theoretical source, he realized the combination of Marxism and Freudianism. Marcuse was deeply influenced by the theory of "alienated labor" in the "Manuscript", inherited Marx's theme of realizing the free and all-round development of human beings, absorbed and drew lessons from Freud's "instinct theory" and "metapsychology" at the same time. Secondly, starting from the objective reality, compared with Marx's era, the objective reality has undergone a major change. The economic crisis cannot immediately destroy the capitalist system, the development of science and technology brings vitality to capitalist production, and society is in a growing abundance. But the problem is that while people's false needs are satisfied, their instincts are completely suppressed, human beings lose their "Eros", and then they lose the internal drive of criticism, negation and transcendence. The liberation of Eros could not be achieved by social reform. Philosophy lost its critical negative power due to its positivist tendency, so Marcuse turned to a new revolutionary form -- aesthetic revolution. Finally, from the characteristics of art itself, literature and art are essentially alienation, because they maintain and protect contradictions. (Marcuse, 2014, p. 53) True art, the true avant-garde of our time, is far from alleviating this distance, far from mocking alienation; It is to strengthen alienation, and to reinforce the incompatibility between alienation and existing reality to such an extent that it rejects any practical application of behavior. (Marcuse, 2001, p. 185) Marcuse believes that only through art alienation can people realize the "sublimation" from "libido" to "Eros", liberate "Eros" and restore the inner dimension of people's criticism, negation and transcendence.

Art alienation is another alienation of the society of "comprehensive alienation" and a sublation of "comprehensive alienation". From the external logic of alienation, it is a kind of "generalized alienation" or "good" alienation. Different from Marx's alienated labor, art alienation is obviously a positive word in Marcuse's works. It is a return to the state of "Ought to Be", that is, return to the qualitative difference between different subjects. Marcuse believed that art is alienation in essence, and the world presented in art works, namely "art reality", should maintain the characteristics of reflection, criticism, negation and transcendence over "objective reality". Taking this as an opportunity to realize the negative thinking in people's heart, so that the "alienated subject" is liberated from the "alienated existence", and then provides the internal motive force for the real social revolution and the realization of the free and all-round development of human beings.

\section{Conclusion}

First, Marx only revealed the alienation of labor in the "Manuscript", while Marcuse used the concept of alienation in a broader sense, so it is a "comprehensive alienation ". The word "alienation" has two basic meanings: "keep at a distance" and "counteraction". When Marx criticized capitalism, he emphasized the 
meaning of "counteraction" or "object control over subject", while Marcuse emphasized the difference between" ought to be" and "to be", which weakened the meaning of confrontation between them.

Second, the alienation logic itself is a kind of speculation, or the defect of the alienation logic is that before we criticize the objective reality, we need to presuppose the original state of an unalienated subject. Marx used the logical structure of "subject-object dichotomy" since Hegel in the process of demonstrating alienated labor (except the fourth aspect of alienated labor). He has realized that Hegel's philosophy is separated from reality, so he takes the current economic facts as the starting point of his theory. Restricted by the logic of alienation, his theory of alienated labor still has a strong speculative color. Marcuse inherited and developed the logical structure of "subject-object dichotomy", he further concretized this structure, and criticized the "to be" state of the society. "Ought to be" is not an original state that has not been alienated, but a social ideal or ultimate goal.

Third, from Hegel to Marx, the status of subject and object in alienation logic is unequal. The subject occupies the dominant position as an unalienated original state, while the object occupies the subordinate position as the product of the subject's essential power, therefore, the sublation of alienation must be the return of the object to the subject. But in Marcuse, the inequality between subject and object, or between "ought to be" and "to be", has been weakened, and replaced by alienation and confrontation between peer subjects.

Fourth, Marx's "alienated labor" is the result of subject's self-movement. But in Marcuse's works, the internal logic of "self-alienation" no longer exists. Alienation is not caused by the subject itself, but by the factor outside the subject. This factor is that the technical rationality in the developed industrial society reconciles all opposing factors.

Fifth, from the external logic of alienation, Marx and Marcuse eventually move towards "good" alienation. Marx believes that alienation would eventually sublate itself. Marcuse believes that the subject of alienation does not have the ability of self-movement, and there is no logical "produce - be produced" relationship between "ought to be" and "to be". Since the sublation of alienation cannot be completed by the subject itself, it must rely on some external force, namely, art alienation. Art alienation is actually a way to avoid reality. It advocates returning to the "ought to be" state in the spiritual world, maintaining inner critical, negative and transcendental dimensions, realizing a revolution in spiritual realm, and laying an ideological foundation for social reform.

In summary, Marcuse basically followed the logical structure of Marx's alienated labor, but he no longer used the concept of "alienation" in a purely speculative sense, but developed it as a tool to criticize social reality. For Hegel, alienation and the sublation of alienation are essentially the self-movement of absolute spirit, which is separated from objective reality. Marx applied the concept of "alienation" to economics in "Economic \& Philosophic Manuscripts of 1844", aiming to criticize the alienation of labor under capitalist conditions and prepare for the demonstration of communism. Although Marx used the concept of alienation to solve practical problems, his theory of alienated labor still retains a speculative color due to the defects of the alienation logic itself. Marcuse is no longer confined the use of alienation to economic sphere, but applies it to all aspects of social life. The self-movement or self-sublation of the subject in the original alienation logic was abandoned, and he affirmed the role of social change, although this change only stayed at the ideological level. Therefore, compared with previous theorists, Marcuse's comprehensive alienation is an improvement, with theoretical and practical significance. Specifically, on the one hand, he promoted the development of alienation theory, and on the other hand, he provided a new idea for later generations to criticize real life.

\section{References}

Han, L. X. (2014). Study of the "Paris Manuscript". Beijing: Beijing Normal University Publishing Group.

Marcuse, H. (2001). The aesthetic dimension (Li Xiaobing, Trans.). Guangxi Normal University Press Group.

Marcuse, H. (2014). One-dimensional man: Studies in the ideology of advanced industrial society (Liu Ji, Trans.). Shanghai: Shanghai Translation Publishing House.

Marx, K., \& Engels, F. (2002). Marx-Engels collected works volume 3 (Central Compilation \& Translation Bureau, Trans.). Beijing: People's Publishing House.

Sun, B. K. (2002). The way of explorers: A study of the philosophical thought of young Marx and Engels. Nanjing: Nanjing University Press.

\section{Copyrights}

Copyright for this article is retained by the author(s), with first publication rights granted to the journal.

This is an open-access article distributed under the terms and conditions of the Creative Commons Attribution license (http://creativecommons.org/licenses/by/4.0/). 